www.nature.com/ja

\title{
Ophiosetin, a new tetramic acid derivative from the mycopathogenic fungus Elaphocordyceps ophioglossoides
}

\author{
Sastia Prama Putri ${ }^{1}$, Hiroshi Kinoshita ${ }^{1}$, Fumio Ihara ${ }^{2}$, Yasuhiro Igarashi ${ }^{3}$ and Takuya Nihira ${ }^{1,4}$
}

The Journal of Antibiotics (2010) 63, 195-198; doi:10.1038/ja.2010.8; published online 5 February 2010

Keywords: Elaphocordyceps ophioglossoides; mycopathogenic fungus; ophiosetin; tetramic acid

Members of the subgroup of tetramic acids (pyrrolidine-2,4-diones) that feature substituted aliphatic bicyclic ring systems, such as equisetin from Fusarium equiseti ${ }^{1}$ and altersetin from Alternaria sp., ${ }^{2}$ show potent antibacterial activities against Gram-positive bacteria, and coniosetin from Coniochaeta ellipsoidea ${ }^{3}$ and CJ-17572 from Pezicula sp. ${ }^{4}$ further exhibit inhibitory activity against multidrug-resistant Staphylococcus aureus and Enterococcus faecalis. In addition to their antimicrobial activity, equisetin-related compounds display various notable biological activities, such as cytotoxicity against P388 tumor cell lines (paecilosetin from Isaria farinosa ${ }^{5}$ ), phytotoxicity against five plant species (trichosetin from the dual culture of Trichoderma harzianum and Catharanthus roseus callus ${ }^{6}$ ) and HIV (human immunodeficiency virus)-1 integrase inhibitory activity (equisetin from Fusarium heterosporum and phomasetin from Phoma sp. ${ }^{7}$ ). This wide range of biological activities makes this class of compounds highly attractive for the discovery of novel bioactive compounds. During our continuous screening for new metabolites from filamentous fungi, ${ }^{8-10}$ an HPLC-diode array detection analysis of the $n$ - $\mathrm{BuOH}$ extract of Elaphocordyceps ophioglossoides showed two compounds with maximum absorbances at $\sim 250$ and $290 \mathrm{~nm}$, which were indicative of the presence of tetramic acid moiety. ${ }^{5,11,12}$ As previous available reports mentioned only limited metabolites from E. ophioglossoides, including the antifungal antibiotic ophiocordin ${ }^{13}$ in 1977 and an antitumor polysaccharide in $1984,{ }^{14}$ we initiated the isolation of the compounds. A detailed analysis of the fungal extract led to the identification of equisetin and a new equisetin analog, which we named ophiosetin ( 1 and 2, Figure 1). This is the first report on either equisetin or an equisetin-related compound produced by this species. In the antimicrobial assay against bacteria, yeasts and filamentous fungi, ophiosetin (1) showed a markedly weaker antibacterial activity compared with the very closely related analogs, equisetin (2) and paecilosetin (3). We herein describe the isolation, structure elucidation and biological activity of ophiosetin (1).

\section{MATERIALS AND METHODS}

\section{General procedures}

UV spectra were recorded on a Hitachi U-3000 spectrophotometer (Hitachi, Tokyo, Japan). NMR spectra were obtained on a JEOL ECP 400 and ECS 400 spectrometer (Jeol, Tokyo, Japan). The ${ }^{1} \mathrm{H}$ and ${ }^{13} \mathrm{C}$ chemical shifts were referenced to the solvent signals $\left(\delta_{\mathrm{H}} \cdot 3.30\right.$ and $\delta_{\mathrm{C}} \cdot 49.1$ in $\left.\mathrm{CD}_{3} \mathrm{OD}\right)$. $\mathrm{HR}$ (high-resolution) FAB-MS were recorded on a JEOL JMS-700 spectrometer. HPLC analyses for screening were carried out on an Agilent HP1100 system (Agilent, Tokyo, Japan) using a Cosmosil 5C18-AR-II column $\left(100 \times 4.6 \mathrm{~mm}^{2}\right.$ i.d.; Nacalai Tesque, Kyoto, Japan). The solvent used to dissolve $\mathbf{1}$ and $\mathbf{2}$ was methanol or chloroform unless stated otherwise. All chemicals, media and reagents were purchased from Wako (Osaka, Japan), unless stated otherwise.

\section{Fermentation and isolation}

The fungus, E. ophioglossoides HF272, was isolated from a soil specimen collected at the Tsuchiyu Hot Spring in Fukushima, Japan. Ascospores released from the specimen were transferred to SMY and incubated at $25^{\circ} \mathrm{C}$ for several days. After mycelia had developed on SMY slants, the strain was kept at $-30{ }^{\circ} \mathrm{C}$ as a stock culture. ${ }^{10}$ The isolated strain was identified as $E$. ophioglossoides according to its morphology by one of the authors (FI) and is deposited at the culture collection of the National Institute of Fruit Tree Science (Ibaraki, Japan) as strain HF272.

The seed culture was prepared as follows: The mycelium of E. ophioglossoides HF272 grown on a slant culture was inoculated into test tubes, each containing $5 \mathrm{ml}$ of the seed medium, SMY (maltose $4 \%$, yeast extract $1 \%$, peptone $1 \%$ ) and cultivated at $25^{\circ} \mathrm{C}$ for 5 days. The seed culture $(5 \mathrm{ml})$ was transferred into $500-\mathrm{ml}$ baffled flasks containing $250 \mathrm{ml}$ of the production medium (SMY supplemented with Diaion HP-20 (Mitsubishi Chemical, Tokyo, Japan) 1\%) and the flasks were cultured at $25^{\circ} \mathrm{C}$ for 21 days under a static condition.

${ }^{1}$ International Center for Biotechnology, Osaka University, Suita, Osaka, Japan; ${ }^{2}$ National Institute of Fruit Tree Science, Tsukuba, Ibaraki, Japan; ${ }^{3}$ Biotechnology Research Center, Toyama Prefectural University, Imizu, Toyama, Japan and ${ }^{4} \mathrm{MU}-\mathrm{OU}$ Collaborative Research Center for Bioscience and Biotechnology, Faculty of Science, Mahidol University, Bangkok, Thailand

Correspondence: Professor T Nihira, International Center for Biotechnology, Osaka University, 2-1 Yamadaoka, Suita, Osaka 565-0871, Japan.

E-mail: nihira@icb.osaka-u.ac.jp

Received 2 December 2009; revised 8 January 2010; accepted 13 January 2010; published online 5 February 2010 

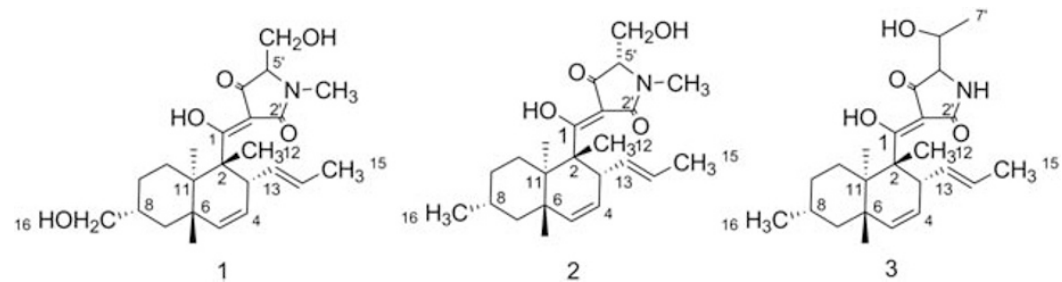

Figure 1 Structure of ophiosetin (1), equisetin (2) and paecilosetin (3).

Table 1 NMR spectroscopic data of ophiosetin (1) in $\mathrm{CD}_{3} \mathrm{OD}$ at $-80^{\circ} \mathrm{C}$

\begin{tabular}{|c|c|c|c|c|c|}
\hline Position & $\delta_{C}{ }^{\mathrm{a}}$ & $\delta_{H}^{\mathrm{b}}$ & DEPT & $H M B C^{\mathrm{b}}$ & $\cos Y$ \\
\hline 1 & 197.3 & - & $\mathrm{C}^{0}$ & $\mathrm{H}-12$ & \\
\hline 2 & 49.8 & - & $c^{0}$ & $\mathrm{H}-12$ & \\
\hline $4^{*}$ & 128.2 & $5.46\left(\mathrm{~m},{ }^{1} \mathrm{H}\right)$ & $\mathrm{CH}$ & & \\
\hline $5^{*}$ & 131.0 & $5.47\left(\mathrm{~m},{ }^{1} \mathrm{H}\right)$ & $\mathrm{CH}$ & & \\
\hline 6 & 39.4 & $1.89\left(\mathrm{~m},{ }^{1} \mathrm{H}\right)$ & $\mathrm{CH}$ & $\mathrm{H}-5$ & $\mathrm{H}-11$ \\
\hline 9 & 37.6 & a: $0.87\left(\mathrm{ddd}, J=12,12,12 \mathrm{~Hz},{ }^{1} \mathrm{H}\right), b: 1.96\left(\mathrm{~m},{ }^{1} \mathrm{H}\right)$ & $\mathrm{CH}_{2}$ & $\mathrm{H}-16$ & a: $\mathrm{H}-9 \mathrm{~b}, \mathrm{H}-8$ \\
\hline $10^{* *}$ & 28.9 & $a: 1.10, b: 2.07\left(\mathrm{~m},{ }^{1} \mathrm{H}\right)$ & $\mathrm{CH}_{2}$ & & a: $\mathrm{H}-10 \mathrm{~b}, \mathrm{H}-11$ \\
\hline 11 & 41.3 & $1.69\left(\mathrm{~m},{ }^{1} \mathrm{H}\right)$ & $\mathrm{CH}$ & H-12, H-5 & H-6, H-10b \\
\hline 12 & 13.9 & $1.46\left(\mathrm{br} \mathrm{s},{ }^{3} \mathrm{H}\right)$ & $\mathrm{CH}_{3}$ & $\mathrm{H}-11, \mathrm{H}-3, \mathrm{H}-2$ & \\
\hline 13 & 132.1 & $5.20\left(\mathrm{~m},{ }^{1} \mathrm{H}\right)$ & $\mathrm{CH}$ & $\mathrm{H}-15$ & \\
\hline 14 & 130.6 & $5.21\left(\mathrm{~m},{ }^{1} \mathrm{H}\right)$ & $\mathrm{CH}$ & $\mathrm{H}-15$ & $\mathrm{H}-15$ \\
\hline $4^{\prime}$ & 192.9 & - & $c^{0}$ & $H-5^{\prime}, H-6^{\prime}$ & \\
\hline $5^{\prime}$ & 69.0 & $3.70\left(\right.$ br.s, $\left.{ }^{1} \mathrm{H}\right)$ & $\mathrm{CH}$ & $\mathrm{N}-\mathrm{CH}_{3}$ & $H-6^{\prime}$ \\
\hline $6^{\prime}$ & 58.8 & a: $3.89\left(\mathrm{dd}, J=12.4,2.7 \mathrm{~Hz},{ }^{1} \mathrm{H}\right), b: 3.95\left(\mathrm{dd}, J=12.4,3.2 \mathrm{~Hz},{ }^{1} \mathrm{H}\right)$ & $\mathrm{CH}_{2}$ & & $H-5^{\prime}$ \\
\hline $\mathrm{N}-\mathrm{CH}_{3}$ & 26.8 & $3.02\left(\mathrm{~s},{ }^{3} \mathrm{H}\right)$ & $\mathrm{CH}_{3}$ & $H-5^{\prime}$ & \\
\hline
\end{tabular}

\section{$*,{ }^{* *}$ exchangeable.}

aRecorded at $100 \mathrm{MHz}$.

becorded at $400 \mathrm{MHz}$.

The whole cell broth $(250 \mathrm{ml} \times 4$ flasks $)$ of strain HF272 after 21 days of cultivation was extracted with ethyl acetate (without saturation with water earlier, $125 \mathrm{ml}$ per flask) by stirring for $3 \mathrm{~h}$. The mixture was separated by filtration using Miracloth (Calbiochem, La Jolla, CA, USA) and the filtrate was extracted three times, each with $250 \mathrm{ml}$ of ethyl acetate. The organic layer was separated from the aqueous layer in an extraction funnel by solvent partition, dried over anhydrous $\mathrm{Na}_{2} \mathrm{SO}_{4}$ and evaporated to provide $\sim 334 \mathrm{mg}$ of extract per 11 of culture. A portion of the crude extract $(200 \mathrm{mg})$ was subjected to reversed-phase column chromatography using a Sep-Pak Vac 35-cc (10 g) $\mathrm{C}_{18}$ cartridge (Waters, Milford, MA, USA) with a step gradient of $\mathrm{CH}_{3} \mathrm{CN}-\mathrm{H}_{2} \mathrm{O}$ $(0: 1,2: 8,4: 6,8: 2$ and $1: 0 \mathrm{v} / \mathrm{v})$. Compound 1 (58.8 $\mathrm{mg} \mathrm{g}^{-1}$ extract) and compound $2\left(8.5 \mathrm{mgg}^{-1}\right.$ extract) were purified by reversed-phase HPLC on a Shiseido Capcell-Pak $C_{18}$ column (Shiseido, Tokyo, Japan) $(5 \mu \mathrm{m}$; $250 \times 10 \mathrm{~mm}^{2}$ i.d.) at $254 \mathrm{~nm}$ with $40 \% \mathrm{CH}_{3} \mathrm{CN}+0.1 \%$ TFA and with $70 \%$ $\mathrm{CH}_{3} \mathrm{CN}+0.1 \%$ TFA, respectively.

Ophiosetin (1). Ophiosetin (1) is a pink-brown oily solid; $[\alpha]^{22}{ }_{\mathrm{D}}-244^{\circ}$ (c 0.02, $\mathrm{CHCl}_{3}$ ); UV (MeOH) $\lambda_{\max }(\log \varepsilon) 204$ (3.42), 252 (4.03), 293 (4.22); ${ }^{1} \mathrm{H},{ }^{13} \mathrm{C}$ NMR, heteronuclear multiple bond coherence (HMBC), see Table 1; HRFAB-MS $m / z[\mathrm{M}+\mathrm{H}]^{+} 390.2295$ (calcd for $\mathrm{C}_{22} \mathrm{H}_{32} \mathrm{NO}_{5}, 390.2280$ ).
Equisetin (2). Equisetin (2) is a pink-brown oily solid; $[\alpha]^{22}{ }_{D}-145^{\circ}$ (c $\left.0.02, \mathrm{CHCl}_{3}\right)$; UV (MeOH) $\lambda_{\max }(\log \varepsilon) 204$ (4.29), $250(3.94), 295(4.01) ;{ }^{1} \mathrm{H}$ NMR data, UV and specific optical rotation were consistent with the data reported in literature, ${ }^{12,15}$ HRFAB-MS $\mathrm{m} / \mathrm{z}[\mathrm{M}+\mathrm{H}]^{+} 374.2340$ (calcd for $\mathrm{C}_{22} \mathrm{H}_{32} \mathrm{NO}_{4}$ 374.2331).

\section{Antimicrobial assay}

Antimicrobial activities of 1, 2 (from E. ophioglossoides) and $\mathbf{3}$ (from Isaria farinosa) were determined by the standardized two-fold broth dilution methods recommended by the Clinical and Laboratory Standards Institute (CLSI, Wayne, PA, USA; formerly the National Committee for Clinical and Laboratory Standards, NCCLS). ${ }^{16}$ The MIC was defined as the lowest drug concentration resulting in complete inhibition of growth after $18 \mathrm{~h}$ of incubation at $37^{\circ} \mathrm{C}$ (bacteria) or $35^{\circ} \mathrm{C}$ (fungi). The following bacteria were used as indicator strains: S. aureus American Type Culture Collection (ATCC) 25923, E. faecalis ATCC 29212, Escherichia coli ATCC 25922 and Pseudomonas aeruginosa ATCC 27853. The following yeasts and filamentous fungi were used: Candida albicans OUT 6266, Saccharomyces cerevisiae ATCC 9804, Aspergillus niger ATCC 6275, Rhyzopus oryzae ATCC 10404 and Geotrichum candidum NBRC 4598. The following standard antibiotics were used as reference compounds: chloramphenicol (antibacterial) and amphotericin B (antifungal). 
The producing strain was isolated from soil collected at the Tsuchiyu Hot Spring in Fukushima, Japan. This fungus was identified as E. ophioglossoides (previously known as Cordyceps ophioglossoides) on the basis of morphological criteria. HRFAB-MS of 1 revealed an ion $[\mathrm{M}+\mathrm{H}]^{+}$at $m / z 390.2295$, corresponding to the molecular formula $\mathrm{C}_{22} \mathrm{H}_{32} \mathrm{NO}_{5}$ (calcd for $\mathrm{C}_{22} \mathrm{H}_{32} \mathrm{NO}_{5}, 390.2280$ ), whereas 2 revealed an ion at $\mathrm{m} / \mathrm{z}$ 374.2340, corresponding to the molecular formula $\mathrm{C}_{22} \mathrm{H}_{32} \mathrm{NO}_{4}$ (calcd for $\mathrm{C}_{22} \mathrm{H}_{32} \mathrm{NO}_{4}, 374.2331$ ). The ${ }^{1} \mathrm{H}$ NMR spectra of 1 and 2 were complicated by the occurrence of several subsets or broadenings of NMR signals, which supported the presence of a tetramic acid moiety because the ${ }^{1} \mathrm{H}$ NMR spectra of tetramic acids frequently display several tautomeric forms. ${ }^{6,7,12}$ Measurement of ${ }^{1} \mathrm{H}$ NMR at $-80^{\circ} \mathrm{C}$ slightly resolved the broadening of signals but significantly improved the measurement of ${ }^{13} \mathrm{C}$ NMR of $\mathbf{1}$ (Supplementary Figures S1 and S2). As in the case of trichosetin, ${ }^{6}$ the signals corresponding to $\mathrm{C} 1, \mathrm{C} 2^{\prime}$ and $\mathrm{C}^{\prime}{ }^{\prime}$ could only be observed when measurement was taken at $-80^{\circ} \mathrm{C}$. Henceforth, all NMR measurements with the exception of NOESY were taken at $-80^{\circ} \mathrm{C}$. NOESY measurement at room temperature was satisfactory and, therefore, measurement at $-80{ }^{\circ} \mathrm{C}$ was not required. Physical and spectroscopic data, including ${ }^{1} \mathrm{H} \mathrm{NMR}$, UV, mass spectral fragmentations and specific rotation of 2 , were in complete agreement with or consistent with those of equisetin. ${ }^{7,12,15}$ A careful comparison of the spectral data between 1 and 2 showed that compound 1 was a new analog of equisetin. Evaluation of the EI mass spectral fragmentation patterns of $\mathbf{1}$ and $\mathbf{2}$ suggested the addition of one oxygen atom in $\mathbf{1}$. The ions at $m / z 170\left(\mathrm{C}_{7} \mathrm{H}_{8} \mathrm{NO}_{4}\right)$ that would be expected to arise from $\alpha$-cleavage between the bridging carbonyl and hydrocarbon domain ${ }^{12}$ were detected in both compounds, whereas the $\mathrm{m} / z 203$ ion corresponding to the carbocyclic domain of $\mathbf{2}$ was not observed in $\mathbf{1}$. Instead, an $\mathrm{m} / \mathrm{z}$ 219 ion was observed, thereby suggesting the addition of one oxygen atom in the carbocyclic domain of 1 . Interpretation of the ${ }^{1} \mathrm{H},{ }^{13} \mathrm{C}$ and 2D NMR data of $\mathbf{1}$ (Table 1) showed that this compound differs from equisetin only by the hydroxylation of the C-16 methyl group attached to C-8 of the decalin moiety. This was supported by the absence of methyl doublets at $\delta 0.92$ in the ${ }^{1} \mathrm{H}$ NMR spectrum and by the presence of a signal at $\delta 3.39$, which is in agreement with the presence of a hydroxymethylene group. Furthermore, DEPT 135 analysis confirmed the absence of a methyl group (C-16), but the presence of a methylene group at $\delta 68.3$ in 1 (Supplementary Figure S3). HMBC correlation between C-7, C-8, C-9 and C-16 further confirmed the proposed structure (Figure 2$)$. Ha-9 showed ddd $(J=12,12,12 \mathrm{~Hz}$ ) on the basis of ${ }^{2} J_{\mathrm{H}, \mathrm{H}}$ coupling with Hb-9 and ${ }^{3} J_{\mathrm{H}, \mathrm{H}}$ couplings with $\mathrm{H}-8$ and $\mathrm{H}-10$. The latter coupling values $(12,12 \mathrm{~Hz})$ indicate axial-axial relationships for $\mathrm{H}-8 / \mathrm{Ha}-9$ and $\mathrm{Ha}-9 / \mathrm{H}-10$ axial (Figure 3 ). The relative configuration of the decalin core of ophiosetin (1) was also determined by a NOESY experiment. The NOESY correlation peaks between Ha- 9 and the bridge-head proton $\mathrm{H}-11$, as well as between $\mathrm{Ha}-9, \mathrm{Hb}-7$ and $\mathrm{H}-16$, indicate the syn relationship of these protons. The second bridgehead proton, $\mathrm{H}-6$, which is located on the other side of the molecule, shows a correlation signal to the methyl group, $\mathrm{H}_{3}-12$. No NOESY correlation can be detected between H-6 and H-11, which indicates a 6,11-trans ring fusion of the two six-membered rings. The cross peak observed between $\mathrm{H}-13$ and $\mathrm{H}-15$ indicates a $13 E$ configuration. The NOESY-derived stereochemistry and conformation of ophiosetin is depicted in Figure 3. NOESY correlations established that the relative configuration of the bicyclic subunit was identical to that in equisetin. As the specific optical rotation $\left([\alpha]^{22}{ }_{D}-244^{\circ}\right)$ is the same in sign to that of equisetin, it has been tentatively assumed that the absolute configuration in the bicyclic part of the molecule is also the same as in equisetin. The absolute configuration of equisetin has

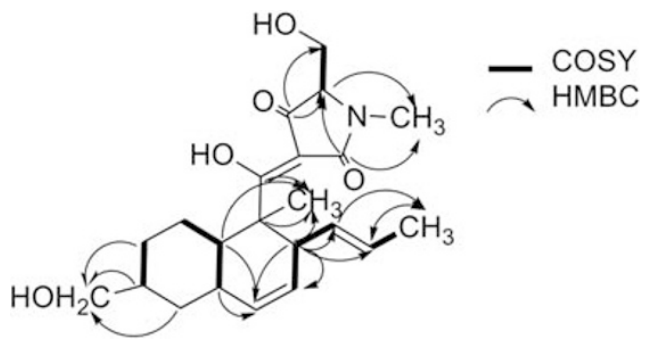

Figure 2 COSY and HMBC correlations of 1.

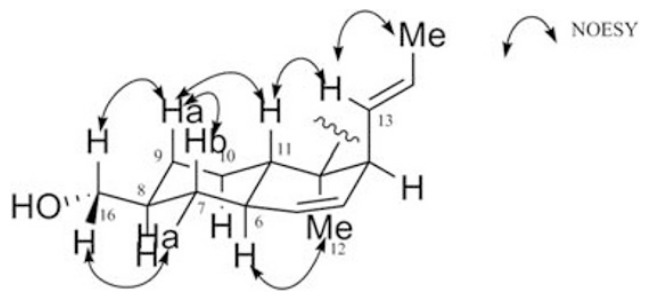

Figure 3 NOESY correlations of 1.

been previously reported, ${ }^{12}$ which was also supported by total synthesis of the compound. ${ }^{17}$ The stereochemistry of phomasetin

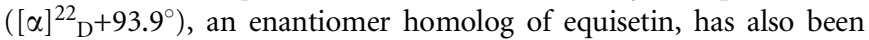
described previously. ${ }^{7}$

The modification at the methyl group of C-16 has never been reported in any equisetin-related compound. To evaluate the effect of the hydroxyl group on the biological characteristics of 1, its antimicrobial activity was assayed. Equisetin (2) and all related compounds that have been tested so far show potent antibacterial activity against Gram-positive bacteria. ${ }^{1-4}$ Consistent with previous reports, in our assay, compounds $\mathbf{2}$ and $\mathbf{3}$ exhibited antibacterial activity against Gram-positive S. aureus (MIC $4 \mu \mathrm{g} \mathrm{ml}^{-1}$ for both 2 and 3) and E. faecalis (MIC $4 \mu \mathrm{g} \mathrm{ml}^{-1}$ for 2 and $2 \mu \mathrm{g} \mathrm{ml}^{-1}$ for 3 ). In addition, compounds $\mathbf{2}$ and $\mathbf{3}$ also showed moderate activity against Gramnegative E. coli (MIC $8 \mu \mathrm{g} \mathrm{ml}^{-1}$ ). However, we could not detect any inhibitory activity of compound $\mathbf{1}$ even at a concentration of $128 \mu \mathrm{g} \mathrm{ml}^{-1}$ against all other tested bacterial strains, except for a weak activity against E. faecalis (MIC $128 \mu \mathrm{g} \mathrm{ml}^{-1}$ ). As for the antifungal activity, compound $\mathbf{3}$ exhibited weak activity (MIC $16 \mu \mathrm{g} \mathrm{ml}^{-1}$ ) against $R$. oryzae and A. niger, but compounds 1 and 2 did not show any antifungal activity at $32 \mu \mathrm{g} \mathrm{ml}^{-1}$. This finding indicates that the modification at $\mathrm{C}-16$ of the decalin moiety in compound 1 results in a drastic decrease in biological activity compared with that of equisetin, whereas it remains unclear at present whether the decreased biological activity is due to the more polar nature of 1 , which may hinder the passage through the cell membrane or affinity toward the target molecules.

\section{ACKNOWLEDGEMENTS}

We thank Mr K Ishidoh of Osaka University for providing an authentic sample of paecilosetin. This study was supported in part by a scholarship from the Ministry of Education, Culture, Sports, Science and Technology (MEXT) of Japan to SPP and by a grant for a 'Research Project in the Field of Biotechnology' from MEXT, the National Research Council of Thailand and from the National Science and Technology Development Agency of Thailand to $\mathrm{TN}$. 
1 Vesonder, R. F., Tjarks, L. W., Rohwedder, W. K., Burmeister, H. R. \& Laugal, J. A. Equisetin, an antibiotic from Fusarium equiseti NRRL 5537, identified as a derivative of N-methyl-2,4- pyrollidone. J. Antibiot. 45, 759-761 (1979).

2 Hellwig, V. et al. Altersetin, a new antibiotic from cultures of endophytic Alternaria spp. Taxonomy, fermentation, isolation, structure elucidation and biological activities. J. Antibiot. 55, 881-892 (2002).

3 Segeth, M. P. et al. Coniosetin, a novel tetramic acid antibiotic from Coniochaetae ellipsoidea. J. Antibiot. 56, 114-122 (2003).

4 Sugie, Y. et al. A novel antibiotic CJ-17,572 from a fungus, Pezicula sp. J. Antibiot. 55, 19-24 (2002)

5 Lang, G., Blunt, J. W., Cummings, N. J., Cole, A. L. \& Munro, M. H. G. Paecilosetin, a new bioactive fungal metabolite from a New Zealand isolate of Paecilomyces farinosus. J. Nat. Prod. 68, 810-811 (2005).

6 Marfori, E. C., Kajiyama, S., Fukusaki, E. \& Kobayashi, A. Trichosetin, a novel tetramic acid antibiotic produced in dual culture of Trichoderma harzianum and Catharanthusroseus callus. Z Naturforsch C 57, 465-470 (2002).

7 Singh, S. B. et al. Equisetin and a novel opposite stereochemical homolog phomasetin, two fungal metabolites as inhibitors of HIV-1 integrase. Tetrahedron Lett. 39, 2243-2246 (1998).

8 Azumi, M. et al. Aurovertins F-H from the entomopathogenic fungus Metarhizium anisopliae. J. Nat. Prod. 71, 278-280 (2008).

9 Lee, S. Y., Kinoshita, H., Ihara, F., Igarashi, Y. \& Nihira, T. Identification of novel derivative of helvolic acid from Metarhizium anisopliae grown in medium with insect component. J. Biosci. Bioeng. 105, 476-480 (2008).
10 Putri, S. P., Kinoshita, H., Ihara, F., Igarashi, Y. \& Nihira, T. Farinomalein, a maleimidebearing compound from the entomopathogenic fungus Paecilomyces farinosus. J. Nat. Prod. 72, 1544-1546 (2009).

11 Nielsen, K. F. \& Smedsgaard, J. Fungal metabolite screening: database of 474 mycotoxins and fungal metabolites for dereplication by standardised liquid chromatographyUV-mass spectrometry methodology. J. Chromatogr. A 1002, 111-136 (2003).

12 Phillips, N. J., Goodwin, J. T., Fraiman, A., Cole, R. J. \& Lynn, D. G. Characterization of the Fusarium toxin equisetin: the use of phenylboronates in structure assignment. J. Am. Chem. Soc. 111, 8223-8231 (1989).

13 Kneifel, H., König, W. A., Loeffler, W. \& Müller, R. Ophiocodin, an antifungal antibiotic of Cordyceps ophioglossoides. Arch. Microbiol. 113, 121-130 (1977).

14 Yamada, H. et al. Structure and antitumour activity of an alkali-soluble polysaccharide from Cordyceps ophioglossoides. Carbohydr. Res. 125, 107-115 (1984).

15 Burke, L. T., Dixon, D. J., Ley, S. V. \& Rodriguez, F. Total synthesis of the Fusarium toxin equisetin. Org. Biomol. Chem. 3, 274-280 (2005).

16 Clinical and Laboratory Standards Institute (CLSI) (a) Methods for Dilution Antimicrobial Susceptibility Tests for Bacteria that Grow Aerobically -7th edn; Approved Standard M07-07, (b) Reference Method for Broth Dilution Antifungal Susceptibility Testing of Yeasts-3rd edn; Approved Standard M27-A3 (c) Reference Method for Broth Dilution Antifungal Susceptibility Testing of Filamentous Fungi-2nd edn; Approved Standard M38-A2, Clinical and Laboratory Standards Institute (CLSI), Wayne, PA, (2007).

17 Turos, E., Audia, J. E. \& Danishefsky, S. J. Total synthesis of the Fusarium toxin equisetin: proof of the stereochemical relationship of the tetramate and terpenoid sectors. J. Am. Chem. Soc. 111, 8231-8236 (1989).

Supplementary Information accompanies the paper on The Journal of Antibiotics website (http://www.nature.com/ja) 